\title{
ELISA for the Detection of Specific IgM and IgG in Human Leptospirosis
}

\author{
By W. J. TERPSTRA, * G. S. LIGTHART AND G. J. SCHOONE \\ WHO/FAO Collaborating Centre for Reference and Research on Leptospirosis, \\ Department of Tropical Hygiene, Royal Tropical Institute, Mauritskade 57, \\ 1092 AD Amsterdam. The Netherlands $\dagger$
}

(Received 5 April 1984; revised 12 September 1984)

\begin{abstract}
ELISA was used to detect specific IgM and IgG in sera from humans with current or past leptospirosis. A serological pattern of a high IgM titre $(\geqslant 1280)$, or moderately increased IgM $(160-640)$ in conjunction with a low IgG titre $(\leqslant 20)$, with serovar copenhageni antigen was characteristic for approximately two-thirds of the sera from serovar icterohaemorrhagiae patients obtained in the first two months of the disease. The antigen was the supernatant of a heated and centrifuged culture of leptospires. Antigens were prepared from serovars copenhageni, grippotyphosa, hardjo and patoc. Sera from patients with icterohaemorrhagiae, grippotyphosa and hardjo infections showed cross-reactivity when different antigens were used. In past infections the IgG titres were clearly higher with the homologous antigen. ELISA for IgM and IgG allows the rapid diagnosis of acute leptospirosis.
\end{abstract}

\section{INTRODUCTION}

Previous studies have indicated that in the acute phase of human leptospirosis, as in other infectious diseases, the antibodies formed are predominantly of the IgM class (Adler \& Faine, 1978). Therefore the demonstration of specific IgM can help in the rapid diagnosis of the disease. This is particularly important in areas where leptospirosis is widespread and residual antibodies of past infection are found in a large part of the population. Adler et al. (1980) showed that in patients with current or recent leptospirosis ELISA could detect specific IgM and IgG. They used homologous sonicated antigens. In their study, sera from patients with a pomona infection cross-reacted with hardjo antigen but the sera from patients with a hardjo infection showed no cross-reactivity with pomona antigen. In a previous study we described ELISA using an antigen prepared from a heated culture of leptospires (Terpstra et al., 1980). This was a 'genus-specific' antigen, which means that an antigen preparation from a single serovar is sufficient for the diagnosis of leptospirosis caused by different serovars. It is not known for how long after the disease specific IgM remains detectable in a patient's blood. The aim of this study was to determine the persistence of specific IgM and IgG in order to evaluate the ELISA, using heat-extracted 'genus-specific' antigen, as a rapid diagnostic test in relation to current, recent and long-past infections. For this it was necessary to examine sera from patients in different periods ranging from early acute disease to many years after the infection. The serovars icterohaemorrhagiae, copenhageni grippotyphosa and hardjo are agents of human leptospirosis in the Netherlands (Wolff, 1964; Terpstra \& Bercovich, 1984). The most common is disease caused by icterohaemorrhagiae and the closely related serovar copenhageni. We have compared IgM and IgG titres over a time course in a first set of investigations. We have compared the specificity of the reaction for a smaller group of sera using antigen preparations from different serovars in a second set of investigations. The microscopic agglutination test was included for reference.

\footnotetext{
$\dagger$ New address: Instituten voor Wetenschappelijk Onderzoek, Koninklijk Instituut voor de Tropen, Meibergdreef 39, 1105 AZ Amsterdam Zuidoost, The Netherlands.
} 


\section{METHODS}

Sera and antigens. A total of 150 blood samples were collected from 88 patients infected by serovars icterohaemorrhagiae or copenhageni. For convenience, these are referred to as icterohaemorrhagiae patients. Blood was collected at different intervals after the onset of disease ranging from a few days to 33 years. From patients with recent infections more than one sample was collected but from patients with long-past infections, particularly 10 or more years after the disease, early samples were no longer available.

For the first set of investigations the sera were divided into five groups of immunologically and clinically relevant phases.

Group A : 1-10 d after the onset of disease; commencement of antibody formation.

Group B : 10-60 d after the onset of disease. During this time antibody formation reaches a peak. Although the course and severity of the disease is quite variable, groups A and B cover approximately the acute phase.

Group C: $2-12$ months after the onset of disease, During this period the patient gradually convalesces.

Group D: 1-5 years after the onset of disease. After one year the patient usually has completely recovered.

Group E : 5-33 years after the onset of disease. This group is only arbitrarily separated from group D.

The sera from these patients were examined with antigen prepared from the serovar copenhageni strain Wijnberg and from the serovar patoc strain Patoc I.

For the second set of investigations, sera from icterohaemorrhagiae patients were divided into two groups: 34 samples from current infections, obtained between 6 and $37 \mathrm{~d}$ after the onset of disease (mean $17 \mathrm{~d}$ ), and 33 sera from past infections, obtained between seven months and 30 years (mean five and a half years). Sera were also obtained from eight patients with current and six with past grippotyphosa infections, and from six with current and four with past hardjo infections. All these sera were examined with antigen prepared from serovar copenhageni strain Wijnberg, serovar grippotyphosa strain Duyster and serovar patoc strain Patoc I. The sera from the hardjo patients were also examined with antigen prepared from serovar hardjo strain Hardjoprajitno. All sera were negative with the latex agglutination test for rheumatoid factor. For negative controls, 133 sera were used. These were obtained from 60 healthy blood donors or from 7 patients with syphilis, 5 with Mycoplasma pneumoniae infection, 10 with hepatitis B, 4 with Yersinia spp. infection, 5 with mumps, 2 with Echo virus infection, 8 with psittacosis and 32 with various autoimmune disorders ( 10 of these were positive for rheumatoid factor).

ELISA. The ELISA test was done as described earlier (Terpstra et al., 1980). Antigen was prepared from a wellgrown culture of leptospires $\left(10^{9} \mathrm{ml}^{-1}\right)$ in EMJH medium. The culture was killed by formalin (final concentration $0.5 \%, \mathrm{v} / \mathrm{v}$ ), heated in a boiling waterbath for $30 \mathrm{~min}$ and centrifuged for $30 \mathrm{~min}$ at $10000 \mathrm{~g}$. The supernatant was used for antigen. This will be referred to as the heat-extracted antigen. In each well of polystyrene microtitre plates (System Cooke, Immulon 129 A ; Dynatech, Plochingen, FRG) $100 \mu$ of the supernatant was left to evaporate at room temperature (1-3d). The plates, which were coated in this way, were stored in a dry place at room temperature. Before use, the plates were thoroughly washed with $0 \cdot 15 \mathrm{M}$-phosphate buffered saline (PBS) $\mathrm{pH} 7 \cdot 2$, containing $0.05 \%$ Tween 20 . Serial twofold dilutions starting at 1 in 10 were made of the sera in PBS containing $0.05 \%$ Tween 20 and $0.5 \%$ bovine serum albumin fraction V. After incubation with the serum dilutions the microtitre plates were washed and subsequently incubated with peroxidase-conjugated anti-human IgM ( $\mu$-chain) or IgG ( $\gamma$-chain) (Institut Pasteur, France) in dilutions of 1 in 500-1 in 2000 depending on the batch and type of antigen and conjugate. The plates were washed again and finally incubated with substrate (5-aminosalicylic acid; Merck). After $2 \mathrm{~h}$ the reaction was read with a Titertek Multiskan. The titre was the last dilution giving an absorbance of more than half the value of a positive control serum diluted 1 in 40 , which is in practice the last dilution which gives a dark brown colour in comparison with the decreasing intensity of the colour in further dilutions. The same positive and negative control sera were used throughout the experiments for reference. The results of single determinations are presented. In introductory studies the ELISA proved to be reproducible within the limits of one dilution step.

Microscopic agglutination test. This was applied as described earlier (Terpstra et al., 1980). Serial twofold dilutions starting at 1 in 10 were made of the sera in PBS. The serum dilutions were incubated with the following serovars: icterohaemorrhagiae (strain Kantorowicz), copenhageni (strain Wijnberg), canicola (strain Hond Utrecht IV), grippotyphosa (strain Duyster), hebdomadis (strain Hebdomadis), saxkoebing (strain Mus 24), hardjo (strain Hardjoprajitno), pomona (strain Pomona), ballum (strain Mus 127), bratislara (strain Jez Bratislava), poi (strain Poi), tarassori (strain Perepelicin), and patoc (strain Patoc I). The titre was the highest dilution giving $50 \%$ agglutination. The data presented are the highest titres observed.

Separate IgM fractions and hulk $\operatorname{Ig} M$. Serum samples from an acutely ill patient which were unreactive in the ELISA for IgM in replicate tests were fractionated by ultracentrifugation. A control serum with clear IgM and IgG activity was included in the experiments. For ultracentrifugation a linear sucrose gradient $5-30 \%$ (w/v) was made in PBS pH 7.2 on a $2 \mathrm{ml}$ layer of $55 \%(\mathrm{w} / \mathrm{v})$ sucrose; $100 \mu \mathrm{l}$ of serum was layered on top of the gradient and centrifuged for $18 \mathrm{~h}$ at $4{ }^{\circ} \mathrm{C}$ at $86287 \mathrm{~g}$ in a Sorvall OTD-65 ultracentrifuge using a Sorvall AH-627 rotor with $17 \mathrm{ml}$ swinging buckets. Separate fractions were tested in the ELISA for specific anti-leptospiral IgM and IgG. Bulk IgM and IgG were determined by Mancini's single radial immunodiffusion test (Mancini et al., 1965). 
Statistical analysis. The differences between antibody titres for various antigens were analysed with the sign test in the first set of experiments as Wilcoxon's rank sign tests gave no clearer results. In the second set of experiments Wilcoxon's test was applied (De Jonge, 1963).

\section{RESULTS}

Serology in icterohaemorrhagiae patients with current and long-past disease

ELISA for IgM using copenhageni and patoc antigen (Table 1). Most sera from patients in group A were already reacting at dilutions $\geqslant 1$ in 40 . The titres with patoc antigen were in general slightly higher $(2 P=0.021)$. A further rise in titre was observed in patients of group $B$, but the difference between the reactions to the antigens was slight and statistically insignificant. The titres in sera from patients of group $C$ showed a sharp decline. In general, the titres with patoc antigen had lower values than with copenhageni antigen but the differences were not statistically significant. The titres to both antigens were very low in the sera of the patients from groups D and $\mathrm{E}$.

Most control sera were negative or had very low titres. Values $\geqslant 40$ were rarely found with either antigen, but with patoc antigen a significantly larger number of sera had low titres $(2 P=0 \cdot 0000)$.

ELISA for IgG using copenhageni and patoc antigen (Table 2). One-third of the sera in group A were reacting at dilutions $\geqslant 1$ in 40 . Titres with patoc antigen were in general higher than with copenhageni antigen $(2 P=0 \cdot 0044)$. Sera from patients in group B showed a further rise in titre and again titres with patoc antigen were in general higher $(2 P=0.045)$. A few sera were unreactive or had low titres. The titres in the sera from the patients of groups C, D and E showed a gradual decrease with both antigens; titres dropped more rapidly and to lower values with patoc antigen. The differences between the two antigens, which were statistically significant $(2 P=0.095$ for group $C, 0.0034$ for group $D, 0.0000$ for group $E)$, became clearer in the course of time.

Most control sera were negative with both antigens. A slightly but significantly larger proportion reacted at low dilutions with patoc antigen than with copenhageni antigen. None of the sera reacted in dilutions $\geqslant 1$ in 40 .

Agglutination (Table 3). Two-thirds of the sera from group A caused agglutination at dilutions $\geqslant 1$ in 100 . All sera from group B were strongly positive. The sera from patients of groups C, D and $E$ showed a gradual decrease in titre.

In the control sera agglutination was almost negligible.

Specific immunoglobulins in current leptospirosis. High IgM titres $(\geqslant 1280$ with copenhageni antigen and $\geqslant 640$ with patoc antigen) were limited to sera obtained from patients of groups $A$ and $B$, the exception being one sample from group $C$ with a titre of 1280 with patoc antigen, obtained from a patient two and a half months after the onset of disease. The combination of a moderately increased IgM titre (160-640 with copenhageni antigen, 160-320 with patoc antigen) and low IgG $(\leqslant 20)$ was also found exclusively in sera obtained from patients of groups A and B. These patterns of reaction were found in $62 \%$ of the sera examined with copenhageni antigen and $70 \%$ of the sera examined with patoc antigen. The frequencies of these patterns for groups $A$ and $B$ are presented in Table 4 . Very high IgG titres ( $\geqslant 2560$ with both antigens) were also found only in sera obtained from patients of groups $\mathrm{A}$ and $\mathrm{B}$, with one exception, discussed below, but these were few in number ( 4 of 80 with copenhageni and 12 of 80 with patoc antigen). High agglutination titres, $\geqslant 10240$, were found in $25 \%$ (20 of 80$)$ of these sera.

One patient had a very high IgG titre $(\geqslant 2560)$ on the tenth day of disease and repeatedly thereafter during a three month period, but negligible IgM values (serum negative or reacting at a dilution of 1 in 10) by ELISA. Agglutination titres to icterohaemorrhagiae antigen in the microscopic agglutination test increased from 160 on the tenth day of disease to 2560 after one month. The IgM and IgG in serum samples of this patient were separated by ultracentrifugation. No specific anti-leptospiral activity of any significance was detected by ELISA in the fractions containing IgM; fractions containing IgG showed specific anti-leptospiral activity to a 


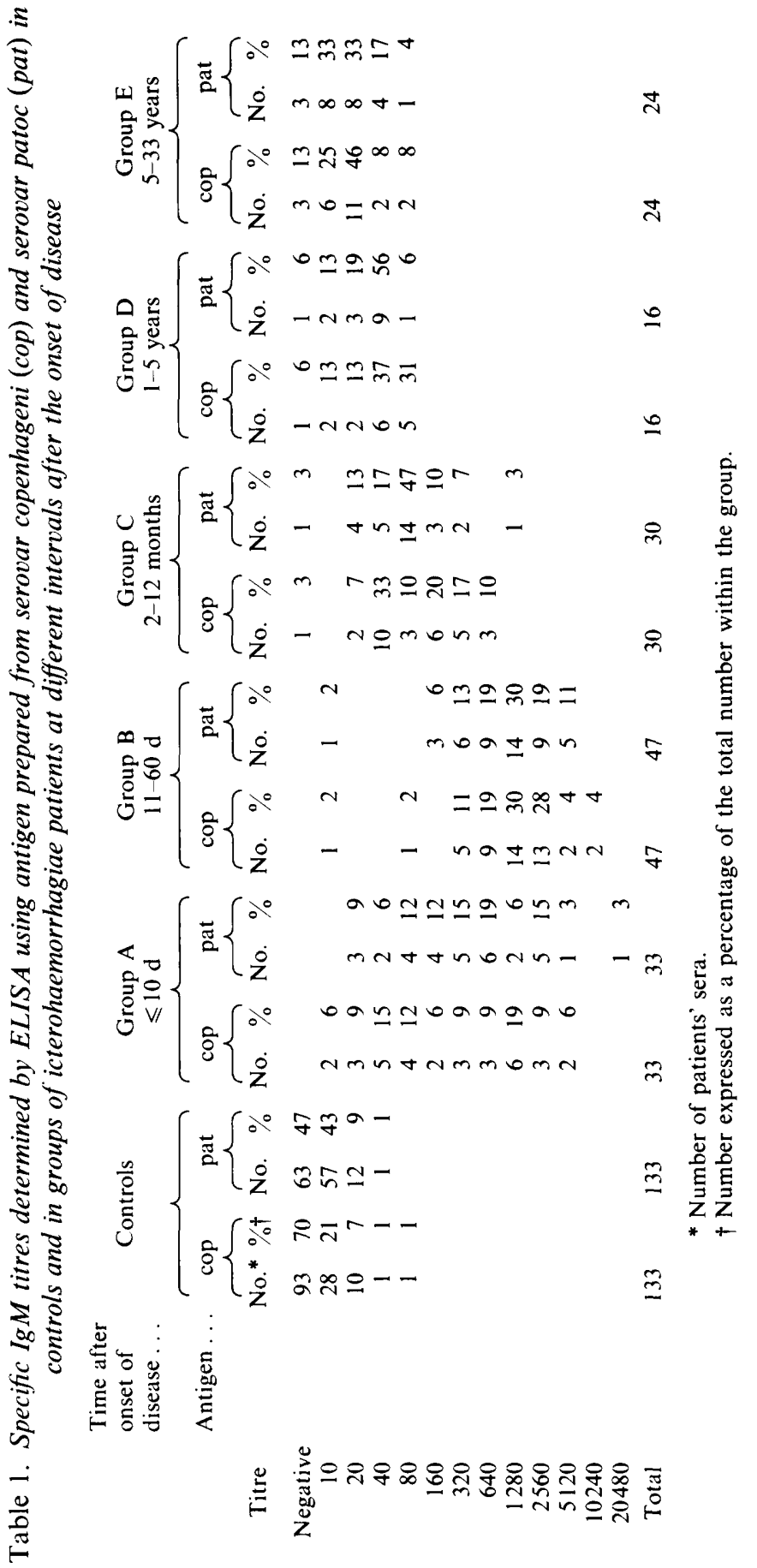




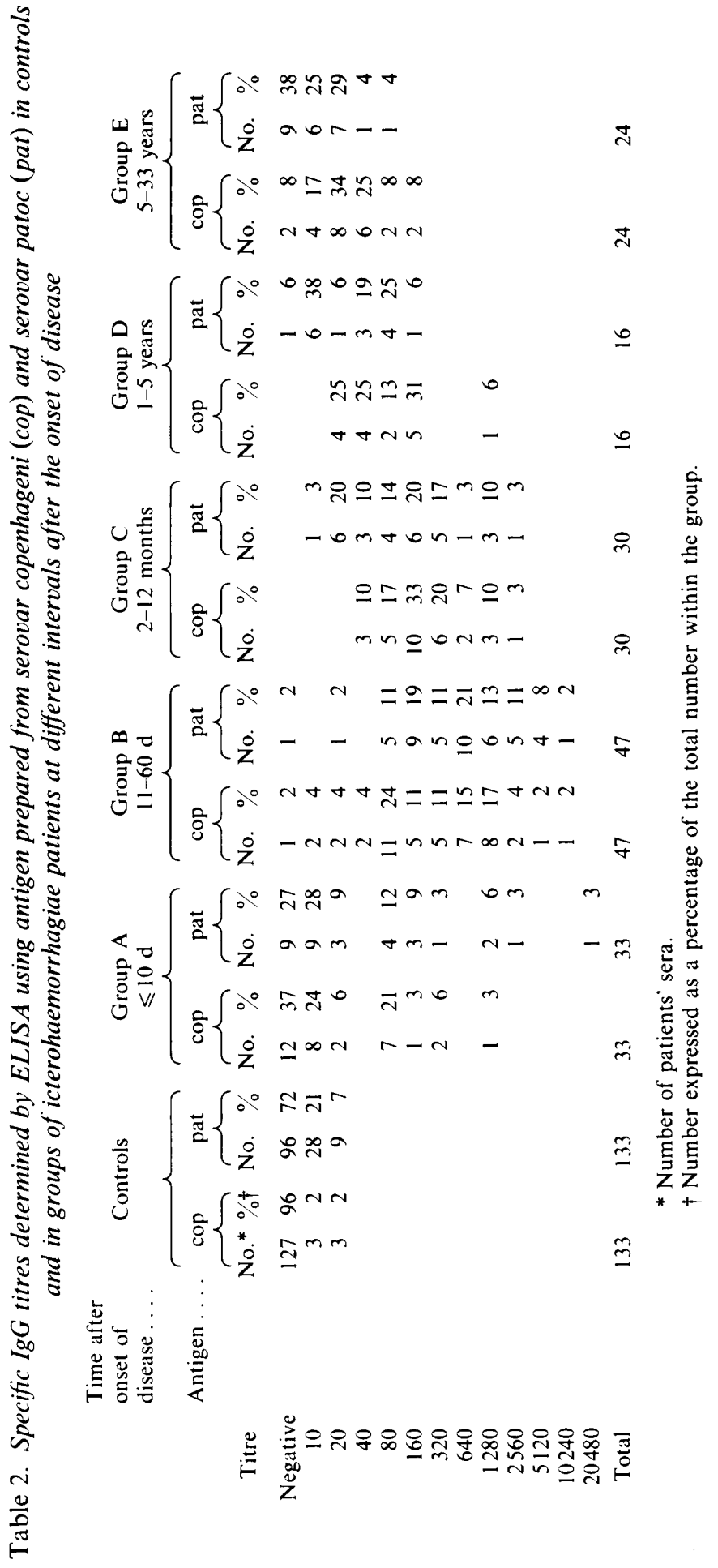




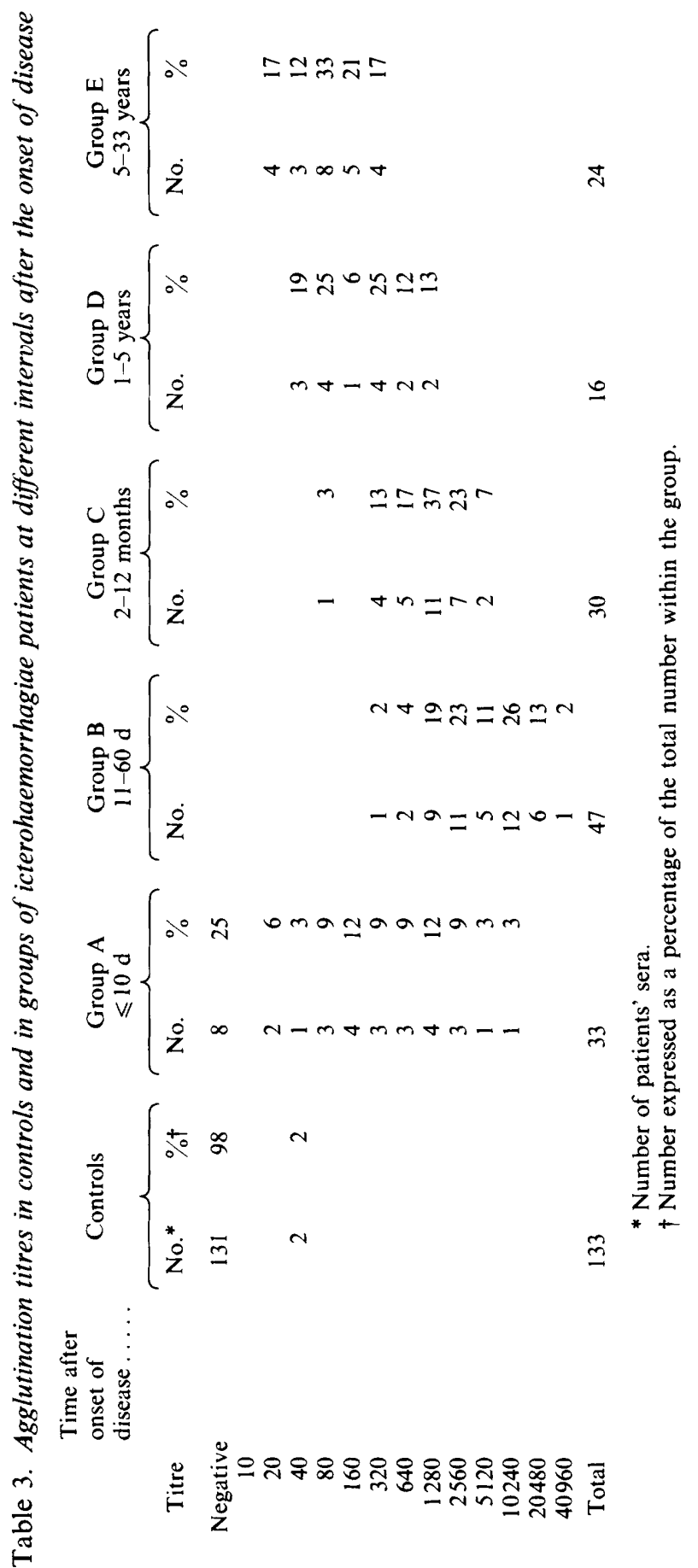


Table 4. Percentages of sera with characteristics of the acute phase of the disease

\begin{tabular}{|c|c|c|c|c|c|}
\hline \multirow[t]{2}{*}{ Antigen } & \multirow[t]{2}{*}{$\ldots$} & \multicolumn{2}{|c|}{ copenhageni } & \multicolumn{2}{|c|}{ patoc } \\
\hline & & $\begin{array}{l}\text { IgM titre } \\
\geqslant 1280\end{array}$ & $\begin{array}{c}\text { IgM titre } \\
160-640 \\
\text { and IgG } \\
\text { titre } \leqslant 20\end{array}$ & $\begin{array}{l}\text { IgM titre } \\
\geqslant 640\end{array}$ & $\begin{array}{l}\text { IgM titre } \\
160-320 \\
\text { and IgG } \\
\text { titre } \leqslant 20\end{array}$ \\
\hline $\begin{array}{l}\text { Group } A^{*} \\
33 \text { patients }\end{array}$ & & 33 & 15 & 45 & 12 \\
\hline $\begin{array}{l}\text { Group B† } \\
47 \text { patients }\end{array}$ & & 66 & 4 & 79 & 0 \\
\hline $\begin{array}{l}\text { Group } A+B \\
80 \text { patients }\end{array}$ & & 53 & 9 & 65 & 5 \\
\hline
\end{tabular}

* Sera obtained $\leqslant 10 \mathrm{~d}$ after the onset of disease.

$\dagger$ Sera obtained $10-60 \mathrm{~d}$ after the onset of disease.

Table 5. Geometrical means of the antibody titres in patients with recent and past (in parentheses) infections of icterohaemorrhagiae, grippotyphosa and hardjo with antigens prepared from serovars copenhageni (cop), grippotyphosa (grip), patoc (pat) or hardjo (har)

$\begin{array}{cccc}\text { Patients } & \text { Antigen } & \text { IgM } & \text { IgG } \\ \text { 34 recent and 33 past } & \text { cop } & 1133(39) & 111(64) \\ \text { icterohaemorrhagiae } & \text { grip } & 602(28) & 104(26) \\ \text { infections } & \text { pat } & 753(29) & 157(24) \\ 8 \text { recent and 6 past } & \text { cop } & 148(20) & 59(<20) \\ \text { grippotyphosa } & \text { grip } & 346(40) & 59(113) \\ \text { infections } & \text { pat } & 160(32) & 54(25) \\ \text { 6 recent and 4 past } & \text { cop } & 640(67) & <20(<20) \\ \text { hardjo infections } & \text { grip } & 402(48) & <20(<20) \\ & \text { pat } & 640(67) & 45(40) \\ & \text { har } & 1280(160) & 71(57)\end{array}$

high titre. Bulk IgM (mean value $1.71 \mathrm{mg} \mathrm{ml}^{-1}$ ) and $\operatorname{IgG}$ (mean value $19 \mathrm{mg} \mathrm{ml}^{-1}$ ) were within normal ranges. A positive control serum had both specific IgM and IgG, in clearly separated fractions.

\section{Comparison of leptospiral antigens by the ELISA test (Table 5)}

Patients with current icterohaemorrhagiae infections. In patients with current icterohaemorrhagiae infections IgM titres with the homologous copenhageni antigen were significantly higher than with the heterologous grippotyphosa $(2 P=0.0000)$ and patoc $(2 P=0.0298)$ antigens. The difference between the two heterologous antigens was insignificant $(2 P=0 \cdot 131)$.

For IgG titres there was hardly any difference between the copenhageni and the grippotyphosa antigen while the difference between the former and patoc antigen was insignificant $(2 P=$ $0 \cdot 252)$. Between the two heterologous antigens the difference was of doubtful significance $(2 P=$ 0.0937).

Patients with past icterohaemorrhagiae infections. IgM titres with copenhageni antigen were usually slightly higher than with grippotyphosa $(2 P=0.051)$ and patoc $(2 P=0.114)$ antigens, but the differences were insignificant. There was no difference between the titres obtained with grippotyphosa and patoc antigen. IgG titres were in general clearly and significantly higher with copenhageni than with grippotyphosa $(2 P=0.0000)$ and patoc $(2 P=0.0000)$ antigens, while again the difference between the two heterologous antigens was negligible.

Patients with current and past grippotyphosa and hardjo infections. In sera from a small group of patients with a grippotyphosa or a hardjo infection a similar trend was observed to that in the sera from the icterohaemorrhagiae patients: in current infections IgM titres were slightly higher 
with the homologous antigen while in past infections IgG titres were clearly higher with the homologous antigen. The numbers of sera in these two groups of patients were too small to allow statistical analysis.

\section{DISCUSSION}

The present study shows that characteristically high $\operatorname{IgM}, \mathrm{IgG}$ and agglutination titres were found only in patients with current leptospirosis. For the characterization of acute disease it was informative to consider IgM titres along with IgG titres. Moderately increased IgM titres in conjunction with low IgG titres were also found exclusively in the first two months of the disease. High IgM titres were found most often between 10 and $60 \mathrm{~d}$ while the combination of moderately increased IgM titres and low IgG titres was most often observed in the first $10 \mathrm{~d}$ of the disease. These two characteristic patterns are valuable for a rapid diagnosis as they were found in approximately two-thirds of the sera obtained from patients during the acute phase of the disease. Characteristically high IgG and agglutination titres were found less frequently. We confirmed the observation by Adler et al. (1980) that in the first few weeks after the onset of disease it was not always possible to demonstrate specific IgG.

In the sera examined in this study, IgM titres reached a peak early in the disease and dropped rather sharply after the acute phase. Moderately increased IgM titres were found up to one year after the infection. For a long time thereafter titres often remained slightly higher than most control values. IgG titres and agglutination titres, after having reached a peak, decreased much more slowly than IgM titres. This is complementary to other studies which have shown the persistence of residual antibodies (Postmus, 1933) of the IgG class (Chernukha et al., 1976).

In the serum of one acutely ill patient IgM titres were negligible during a three month period. The agglutination titre showed an increase which was suggestive of an acute infection, possibly a reinfection. This exceptional case shows that current infections are not necessarily associated with the presence of specific IgM.

A larger proportion of the control sera reacted at low dilutions with patoc than with copenhageni antigen. However, this observation is of little practical impact as only very few of the control sera reacted at dilutions $\geqslant 1$ in 40 , so that all sera reacting with both antigens over this threshold level can be considered positive. Comparison of different antigens showed that the highest IgM titres were usually found with the homologous antigen. However, this observation is of little significance as the differences were of the order of one dilution step. In many sera from long-past infections IgG could still be detected by the homologous antigen but seldom by the heterologous antigens. Therefore, in an epidemiological survey the significance of screening for IgG may lie in detecting serogroup specificity in residual antibodies, while screening for IgM can detect recent infections.

In leptospirosis, genus-specific tests tend to become positive early in the disease and also to revert to negative relatively early (Turner, 1968). Palit \& Gulasekharam (1973) observed that only IgM antibodies reacted in the haemagglutination test with erythrocyte-sensitizing substance (ESS). Broadly reactive genus-specific antigen or antigens such as ESS might have a high affinity for $\operatorname{lgM}$. On the other hand, heat-extracted antigen, prepared from saprophytic patoc and therefore presumably genus-specific, was able to bind not only IgM but also IgG in ELISA. The difference between the results with ESS and with heat-extracted antigen is not necessarily contradictory. ESS is a partly purified ethanol extract of leptospires (Chang \& McComb, 1954) consisting of a single antigen fraction, as was shown by crossed immunoelectrophoresis using rabbit antiserum, while heat-extracted antigen consists of four fractions probably with different specificities (Terpstra \& Schoone, 1983). Moreover, IgG antibodies even if they bind to ESS may agglutinate sensitized erythrocytes poorly in comparison with IgM which has more antigen-binding sites. Many years after the infection, specific IgG could be demonstrated with heat-extracted antigen prepared from copenhageni in serum from former icterohaemorrhagiae patients. This may indicate that this antigen contains serogroup and maybe even type-specific fractions apart from the broadly reactive genus-specific fraction or fractions. 
An advantage of ELISA using serial serum dilutions is that the influence of possible inter-well variation (Burt et al.,1979; Chessum \& Denmark, 1978; Kricka et al., 1980) on the test results is reduced. To obtain reliable results with ELISA it was of utmost importance that the heatextracted antigen was of a good quality. Each batch of antigen was carefully tested for its antigen-binding capacity and unsatisfactory batches were discarded. Abundant growth in the culture was one of the controllable prerequisites for a good antigen. A major advantage of the heat-extracted antigen is its stability. It could be stored for a long time both in the liquid state and coated to polystyrene. Heat-extracted antigens from copenhageni and hardjo coated to polystyrene plates showed no loss of antigen activity after storage for three and a half years and one year, respectively, at room temperature.

It is concluded that the ELISA test described in this paper, by the detection of characteristic patterns of IgM and IgG in the acute phase of the disease, makes an important contribution to the rapid diagnosis of human leptospirosis. This study shows that the disease can be diagnosed with a single antigen, which can be prepared from different serovars.

We want to express our sincere gratitude to the patients and doctors who provided samples. We thank Mr A. van Tilborgh of the section of Epidemiology and Statistics of our Institute for his support on the statistical aspects of this study and Dr E. P. Wright for her advice in the preparation of the manuscript.

\section{REFERENCES}

ADLER, B. \& FAINE, S. (1978). The antibodies involved in the human immune response to leptospiral infection. Journal of Medical Microbiology 11, 387400.

Adler, B., Murphy, A. M., Locarnini, S. A. \& Faine, S. (1980). Detection of specific anti-leptospiral immunoglobulins $M$ and $G$ in human serum by solidphase enzyme linked immunosorbent assay. Journal of Clinical Microbiology 11, 452-457.

Burt, S. M., Carter, T. J. N. \& Kricka, L. J. (1979). Thermal characteristics of microtitre plates used in immunological assays. Journal of Immunological Methods 31, 231-236.

Chang, R. S. \& МсСомв, D. (1954). Erythrocyte sensitizing substances from five strains of leptospirae. American Journal of Tropical Medicine and Hygiene 3, $481-489$.

Chernukha, Yu. G., Shiskina, Z. S., Baryshev, P. M. \& Kokovin, I. L. (1976). The dynamics of IgM- and IgG-antibodies in leptospiral infection in man. Zentralblatt für Bakteriologie, Mikrobiologie und Higiene (Abteilung I, Originale A) 236, 336-343.

Chessum, B. S. \& Denmark, J. R. (1978). Inconstant ELISA. Lancet i, 161 .

DE JONGE, H. (1963). Inleiding tot de Medische Statistiek. Deel $1.2^{\mathrm{e}}$ druk. Verhandeling ran het Nederlands Instituut roor Praeventieve Geneeskunde $X L I$.

Kricka, L. J., Carter, T. J. N., Burt, S. M., KenNedy, J. H., Holder, R. L., Halliday, M., TELFORD, M. E. \& W ISDOM, G. B. (1980). Variability in the adsorption properties of microtitre plates used as solid supports in enzyme immunoassay. Clinical Chemistry 26, 741-744.

Mancini, G., Carbonara, A. O. \& Heremans, J. F. (1965). Immunochemical quantitation of antigens by single radial immunodiffusion. Immunochemistry $\mathbf{2}$, 235.

Palit, A. \& Gulasekharam, J. (1973). Genus-specific leptospiral antigen and its possible use in laboratory diagnosis. Journal of Clinical Pathology 26, 7-16.

Postmus, S. (1933). Het beloop van de seroreactie bij oudlijders aan de ziekte van Weil. Nederlands Tijdschrift ioor Geneeskundè 23, 2648-2651.

Terpstra, W. J. \& Bercovich, Z. (1984). Melkerskoorts, de leptospirose van veehouders. Nederlands Tijdschrift voor Geneeskunde 22, 1040-1044.

Terpstra, W. J. \& Schoone, G. J. (1983). Analysis of leptospira antigens by crossed immunoelectrophoresis. Scandinatian Journal of Immunology 18, 113-121.

Terpstra, W. J., Ligthart, G. S. \& Schoone, G. J. (1980). Serodiagnosis of human leptospirosis by enzyme-linked-immunosorbent-assay (ELISA). Zentralblat für Bakteriologie. Mikrobiologie und Hygiene (Ahteilung I, Originale A) 247, 400-405.

TURner, L. H. (1968). Leptospirosis II. Serology. Transactions of the Royal Society of Tropical Medicine and Hyiene 62, 880-899.

WOLFF, J. W. (1964). The relation of animal hosts of parasitic leptospires in the Netherlands with human leptospirosis. Tropical and Geographical Medicine 1, 2-8. 